\title{
SISTEM INFORMASI RAGAM KEBUDAYAAN DI PROVINSI INDONESIA BERBASIS ANDROID
}

\author{
Dandy Herlambang ${ }^{1}$, Imam Himawan ${ }^{2}$, Aswin Fitriansyah ${ }^{3}$ \\ Program Studi Teknik Informatika, Fakultas Teknik dan Ilmu Komputer, \\ Universitas Indraprasta PGRI \\ Jalan Raya Tengah No 80, Kelurahan Gedong, Pasar Rebo, Jakarta Timur \\ dandy.herlambang04@gmail.com ${ }^{1}$, imamhimawann@gmail.com² ${ }^{2}$, aswin.fitriansyah@gmail.com ${ }^{3}$
}

\begin{abstract}
Abstrak
Kebudayaan merupakan bukti autentik dari suatu negara. Indonesia buktinya, bahwa negara kita ini memilik berbagai macam kebudayaan dari sabang sampai merauke. Kebudayaan adalah salah satu peninggalan dari leluhur kita terdahulu, dimana kita harus selalu mengingat, mengenal, melestarikan kebudayaan itu sendiri. Banyak warga negara kita mulai melupakan kebudayaan kita tercinta ini, karena sudah banyak kebudayaan asing yang masuk ke negara kita ini. Mengenal berbagai macam kebudayaan asing merupakan hal yang boleh kita ketahui, tetapi alangkah lebih baik jika kita mengenal kebudayaan negara kita sendiri. Untuk mempermudah setiap warga negara kita dalam mengenal kebudayaan Indonesia, maka dibuatlah sebuah aplikasi sistem informasi berbasis kan teknologi terkini yaitu android. teknologi merupakan perkembangan masa kini dimana hampir semua hal dapat dilakukan melalu teknologi. Maka dari itu penggabungan sebuah teknologi dengan kebudayaan Indonesia cukup dibutuhkan agar semua warga negara kita dapat menggunakan aplikasi ini di smartphone mereka masing-masing dan tetap mengenal bahkan dapat melestarikan kebudyaan Indonesia itu sendiri.
\end{abstract}

Kata Kunci: Ragam Kebudayaan, provinsi, android, grounded research.

\begin{abstract}
Culture is authentic evidence of a country. Indonesia is proof, that our country has a variety of cultures from sabang to merauke. Culture is one of the relics of our previous ancestors, where we must always remember, know, preserve the culture itself. Many of our citizens are starting to forget our beloved culture, because there are already many foreign cultures that enter our country. Knowing various kinds of foreign cultures is something we can know, but it would be better if we know the culture of our own country. To make it easier for every citizen of our country to know Indonesian culture, an information system application based on the latest technology is android. Technology is a development today where almost anything can be done through technology. Therefore, the merging of a technology with Indonesian culture is needed so that all our citizens can use this application on their respective smartphones and still know and can even preserve the existence of Indonesia itself.
\end{abstract}

Keywords: Kind of Culture, Province, Android, Grounded Research.

\section{PENDAHULUAN}

Berhubungnya dengan masa kini yaitu masa dimana hampir semua hal menggunakan teknologi baik itu informasi, penjualan, pembelian, pendataan, pembelajaran dan lain-lain. Maka dari itu peneliti ingin membuat sebuah program untuk membantu para penggunanya yang tidak mengetahui dan mengenal ragam kebudayaan yang dimiliki oleh negara kita Indonesia.

Kebudayaan adalah peninggalan atau bisa kita bilang kebiasaan para leluhur kita dimasa lalu yang selalu dilaksanakan melalui berbagai macam acara adat mereka. Kebudayaan manusia mustahil tanpa bahasa karena bahasa merupakan faktor utama yang akan menentukan terbentuknya kebudayaan (Maulana et al., 2020). Dari kata "budaya" dapat diciptakan kata kerja "mem- budayakan," "di-budaya-kan," "ter-budaya," "pem-budaya-an," "usaha kebudayaan", dan terakhir yang paling penting adalah membentuk kata "budaya" menjadi kata "ke-budaya-an" (Marzali, 2014). Negara kita Indonesia terdiri dari 34 provinsi dari sabang sampai merauke yang memiliki beragam kebudayaan yang selalu memiliki nilai lebih. Untuk tetap menjaga budaya kita agar dapat kita 
kenal hingga ke generasi selanjutnya ialah dengan melakukan kegiatan yang leluhur kita lakukan sebelumnya dengan selalu melestarikan dan mempelajarinya sampai sekarang.

Menurut (Sutabri, 2013) Teknologi Informasi meliputi segala hal yang berkaitan dengan proses, penggunaan sebagai alat bantu, memanipulasi, dan pengelolahan informasi sedangkan Teknologi Komunikasi adalah segala sesuatu yg berkaitan dengan penggunaan alat bantu unutk memprosess dan mentransfer data dari perangkat yang satu ke yang lain (Saputra et al., 2018).Para pengguna biasanya akan sangat bosan apabila dalam pemberian materi pengenalan tersebut hanya dalam bentuk buku panduan dan penyampaian manusia. Dalam hal tersebut akan sangat tidak efektif terutama dalam segi ukuran dan beban yang dibawa, apalagi buku panduan bukan lah sebuah hal yang selalu kita gunakan, dan penyampaian manusia yang tidak lain membosankan bahkan ada kesalahan dalam pengucapannya. Agar pengguna mudah membawa, mengingat dan tertarik dalam penyampaiannya, maka dari itu peneliti akan membuat sebuah aplikasi berbasis android yang bertujuan untuk meringankan dan mempermudah setiap pengguna dalam mempelajari dan mengenal hal yang tidak mereka ketahui sebelumnya mengenai kebudayaan Indonesia. Android adalah sistem operasi berbasis Linux yang dirancang untuk perangkat bergerak layar sentuh seperti telepon pintar dan komputer tablet. Android awalnya dikembangkan oleh Android, Inc dengan dukungan finansial Google, yang kemudian membelinya pada tahun 2005 (Kusniyati \& Pangondian Sitanggang, 2016).

\section{PENELITIAN RELEVAN}

Penelitian pertama adalah penelitian yang dilakukan oleh Hendra Gunawan, dengan judul Rancang Bangun Media Pembelajaran Pengenalan Ragam Budaya Indonesia Berbasis Android. Penelitian Aplikasi media pembelajaran Budaya Tradisional Indonesia dapat dipergunakan oleh para pengguna sebagai media alternatif untuk mengetahui sejauh mana pengetahuan mengenai budaya untuk kategori tarian, lagu, rumah, pakaian, alat musik, dan senjata tradisi yang ada di Indonesia, kapanpun dan dimanapun melalui Aplikasi berbasis Android ini (Gunawan et al., 2020).

Penelitian kedua adalah penelitian yang dilakukan oleh Fatin Furiyanti, dengan judul Aplikasi Tebak Gambar dan Pengenalan Pakaian Adat Berbasis Android. Penelitian ini bertujuan untuk mempelajari tentang pakaian adat indonesia yang berupa tebak gambar dengan soal pilihan ganda dan langsung bisa belajar di aplikasi tebak gambar dan pengenalan pakaian adat indonesia ini (Furiyanti, 2018).

Penelitian ketiga adalah penelitian yang dilakukan oleh Yulisman dan Serdiansah dengan judul Aplikasi Pengenalan Kebudayaan Provinsi Riau berbasis Android. Dari hasil penelitian ini, maka dapat disimpulkan setelah pembuatan dan pengembangan serta pengujian Aplikasi Pengenalan Kebudayaan Provinsi Riau di SMA Negeri 1 Cerenti Berbasis Android ini bahwa Aplikasi pengenalan kebudayaan Provinsi Riau ini dapat membantu guru, dapat meningkatkan ketertarikan dan minat belajar para peserta didik/siswa di SMA Negeri 1 Cerenti dalam mempelajari kebudayaan yang ada di Provinsi Riau (Yulisman \& Serdiansah, 2019).

\section{METODOLOGI PENELITIAN}

Desain penelitian yang peneliti lakukan adalah dengan menggunakan metode grounded research. Metode grounded research yaitu metode penelitian yang berdasarkan fakta dengan tujuan dapat menetapkan konsep, mengembangkan sebuah teori, pengumpulan dan analisis data dalam waktu yang bersamaan.

Grounded theory yang secara teknik bersifat induktif yang dikembangkan secara ilmiah ditemukan pada tahun 1967 oleh Barney G. Glaser dan Anselm L. Strauss dengan diterbitkannya buku berjudul "The Discovery of Grounded Theory". Grounded research diperkenalkan di Indonesia pada tahun 1970-an, dengan diselenggarakannya pelatihan riset ilmu sosial bagi ilmuwan Indonesia pertama kali di Surabaya, kemudian di Ujung Pandang, dan Banda Aceh. Pengembangan awal grounded research adalah dalam bidang sosiologi. Istilah grounded (diperkenalkan oleh Glaser dan Strauss) mengacu pada kondisi bahwa teori yang dikembangkan atau riset tersembunyi, atau disebut berakar pada data dari mana teori tersebut diturunkan (Ayu \& Budiasih, 2013). Selain itu, penelitian jenis ini bertujuan untuk mengspesifikasikan konsep serta memverifikasi terhadap teori yang sedang dikembangkan dan diperiksa dalam hubungannya dengan data yang ditemukan. Dalam penelitian grounded research metode yang digunakan adalah studi perbandingan yang bertujuan 
untuk menentukan seberapa besar suatu gejala tersebut berlaku untuk umum. Beberapa langkah dalam grounded research, yaitu Merumuskan masalah penelitian, Melakukan penjaringan data, Analisis data, Penyusunan teori, Validasi teori, dan Penulisan laporan penelitian.

\section{HASIL DAN PEMBAHASAN}

Melihat permasalahan yang ada saat ini adalah proses pembelajaran masih menggunakan metode konvensional, terutama dalam pengenalan kebudayaan yang ada di provnisi Indonesia. Maka dari itu peneliti membuatkan sebuah aplikasi mengenai informasi kebudayaan di provinsi Indonesia melalui media Smartphone berbasis Android. Dalam pembuatan dan pengembangan sebuah sistem diperlukan analisa dan perancangan dari sistem yang akan dibuat. Analisis sistem ini bertujuan untuk mengidentifikasi masalah yang ada pada sistem / aplikasi serta memberikan gambaran terhadap sistem/aplikasi yang akan dirancang (Rahmat \& Legiman, 2019).

Flowchart adalah cara penulisan algoritma dengan menggunakan notasi grafis.Flowchart merupakan gambar atau bagan yang memperlihatkan urutan atau langkah-langkah dari suatu program dan hubungan antar proses beserta pernyataannya. Gambaran ini dinyatakandengan symbol (Romzi, 2012). Berikut adalah perancangan flowchart dan tampilan hasil uji coba untuk Sistem Infromasi Ragam Kebudayaan di Provinsi Indonesia Berbasis Android.

\section{Menu Utama}

Flowchart

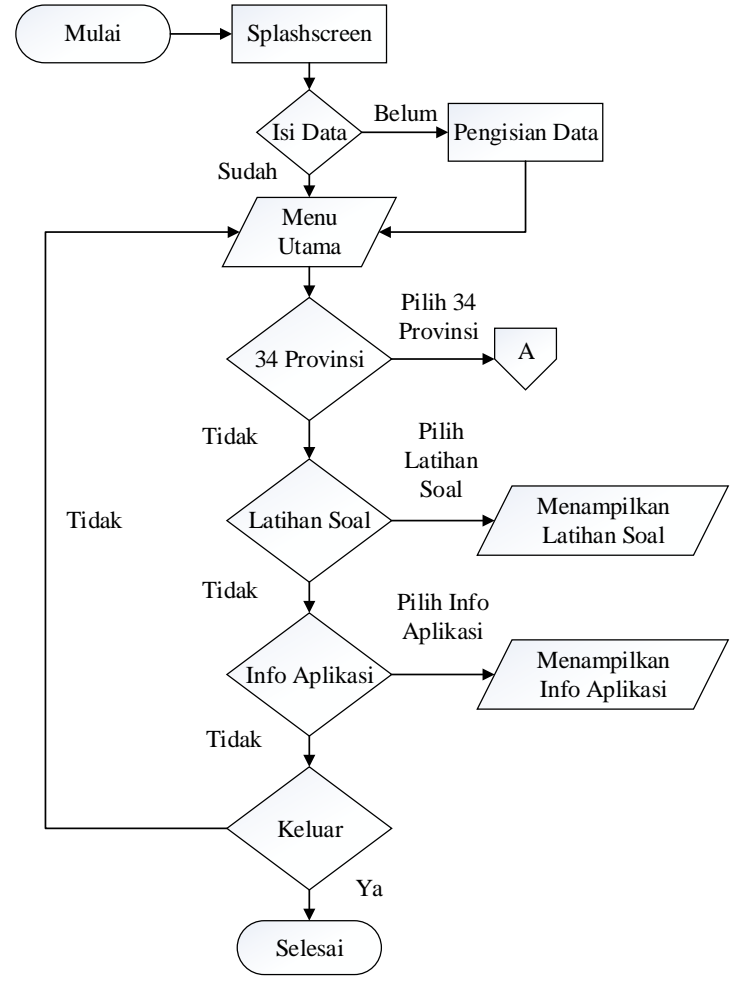

Gambar 1. Flowchart Menu Utama 
Jurnal Riset dan Aplikasi Mahasiswa Infarmatika (JRAMI)

Vol 03 № $\mathrm{Cl}$ Tahun 2022

e-ISSN : 2715-8756

Menu 34 Provinsi

Flowchart Menu 34 Provinsi

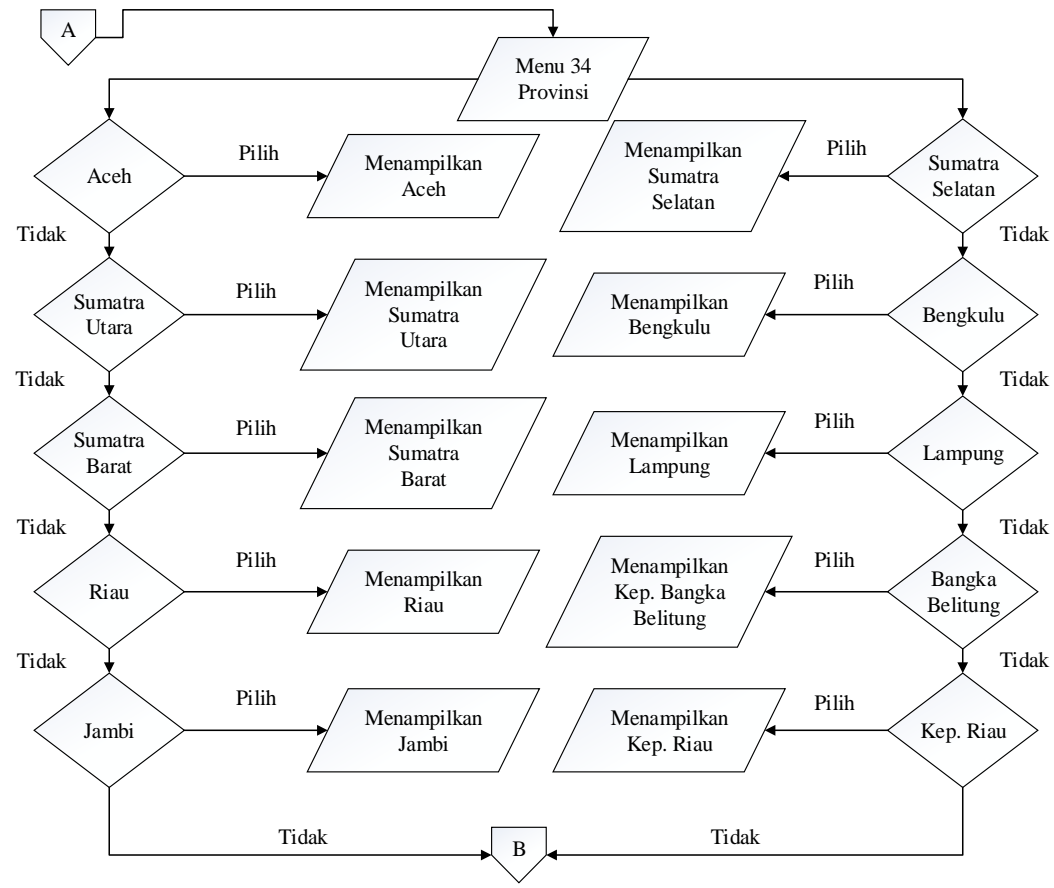

Gambar 2. Flowchart Menu 34 Provinsi

\section{Menu 34 Provinsi2}

Flowchart Menu 34 Provinsi2

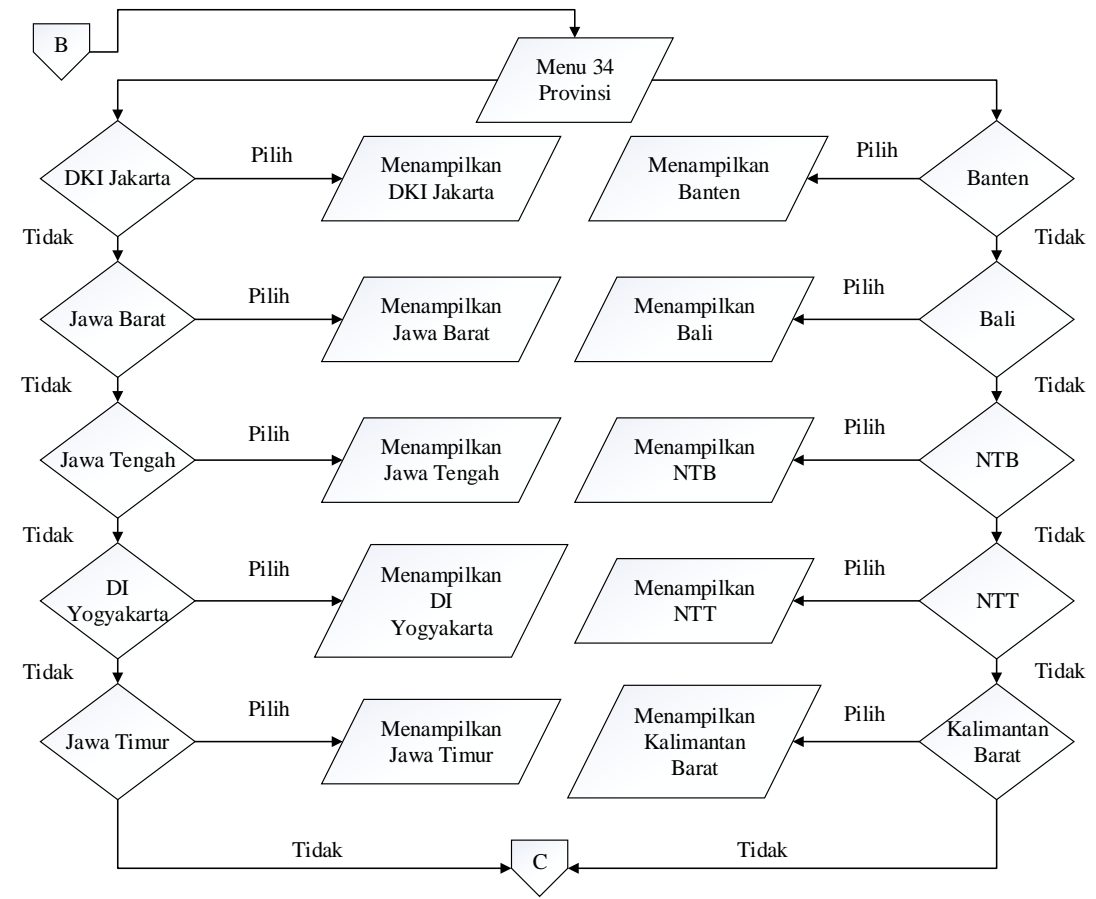

Gambar 3. Flowchart Menu 34 Provinsi2 


\section{Menu 34 Provinsi3}

Flowchart Menu 34 Provinsi3

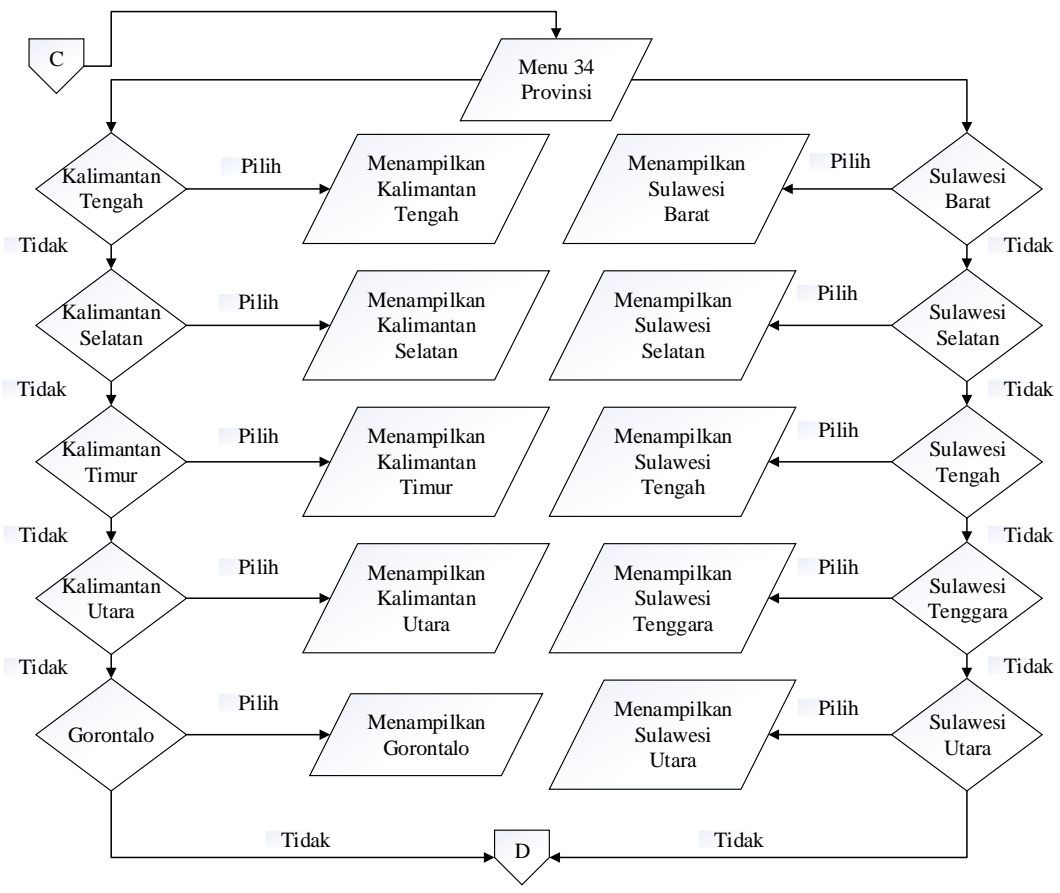

Gambar 4. Flowchart Menu 34 Provinsi3

\section{Menu 34 Provinsi4}

Flowchart Menu 34 Provinsi4

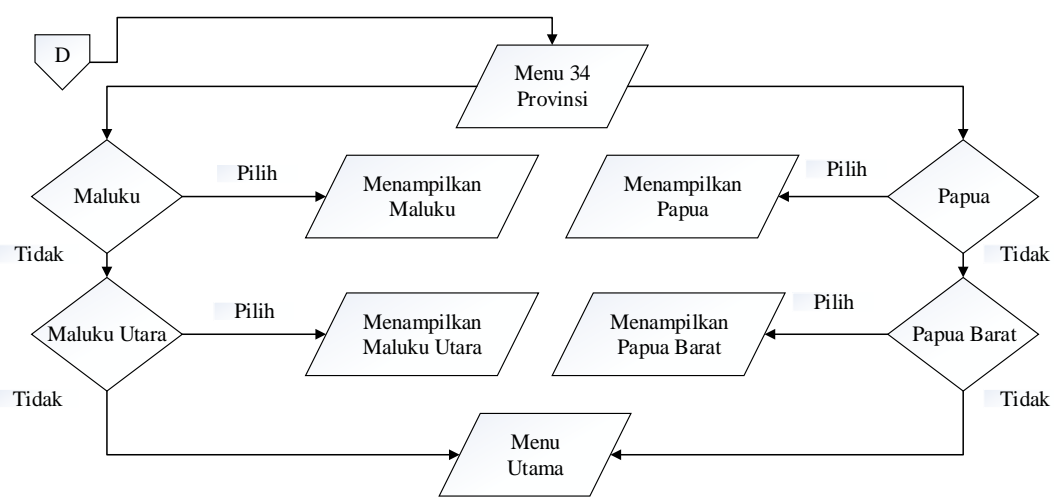

Gambar 5. Flowchart Menu 34 Provinsi4 


\section{Menu Menampilkan Provinsi}

Flowchart Menu Menampilkan Provinsi

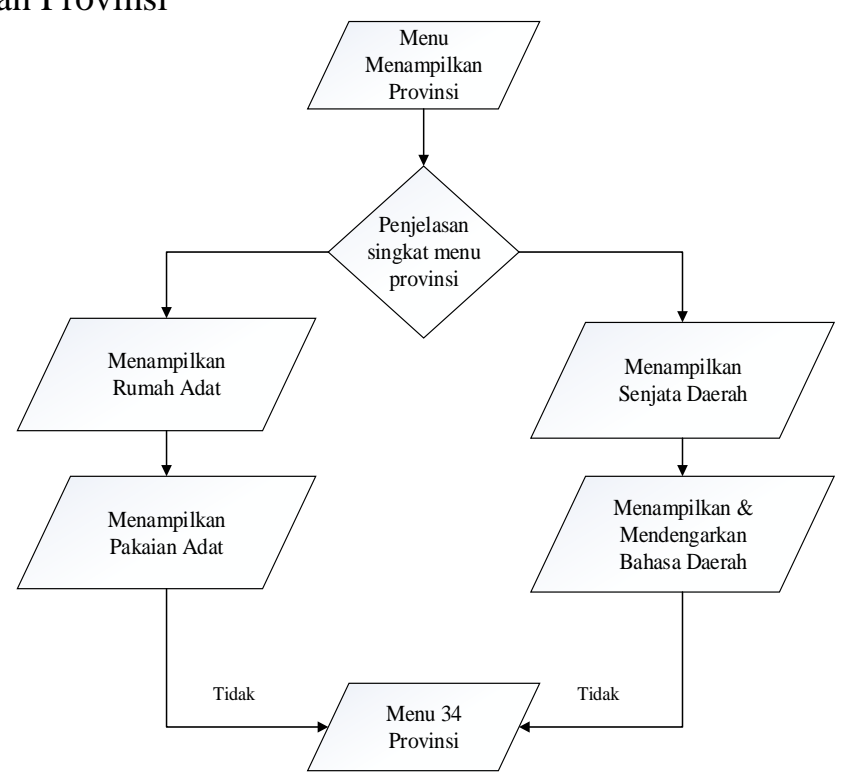

Gambar 6. Flowchart Menu Menampilkan Provinsi

\section{Tampilan Aplikasi}

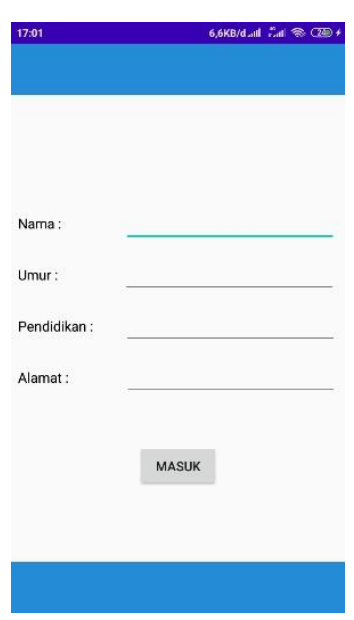

Gambar 7. Tampilan Menu Isi Data

Pada tampilan Menu Isi Data terdapat form pengisian data agar data tersimpan di dalam database 


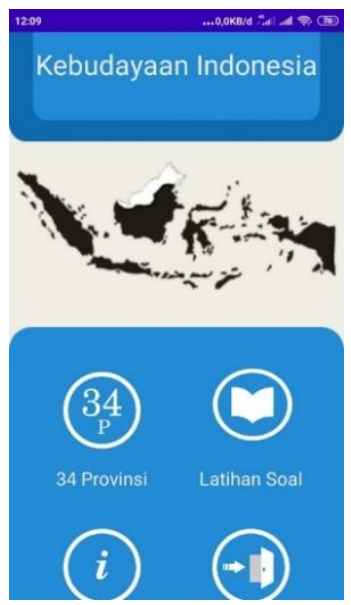

Gambar 8. Tampilan Menu Utama

Pada tampilan Menu Utama terdapat 4 tombol menu yang dapat diakses, antara lain adalah 34 Provinsi, Latihan Soal, Info Aplikasi, dan Keluar

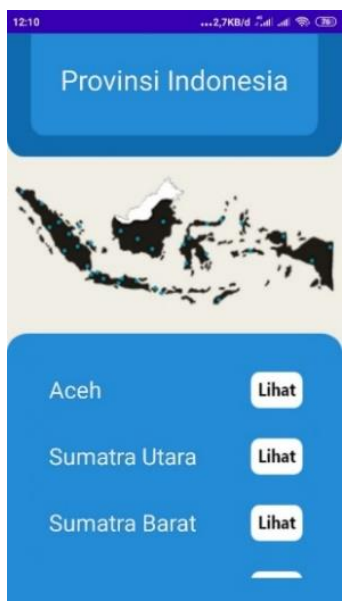

Gambar 9. Tampilan Menu 34 Provinsi

Pada tampilan Menu 34 Provinsi terdapat 34 tombol lihat yang dapat diakses dan menapilkan setiap nama provinsi Indonesia

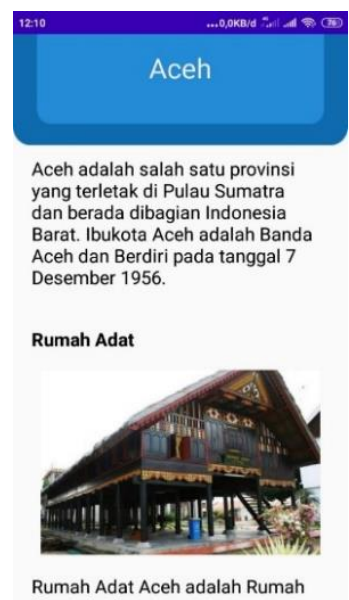

Gambar 10. Tampilan Menu Tampil 34 Provinsi 
Pada tampilan Menu Tampil 34 Provinsi terdapat informasi kebudayaan pada setiap provinsinya, antara lain Rumah Adat, Pakaian Adat, Senjata Tradisional, dan Bahasa Daerah
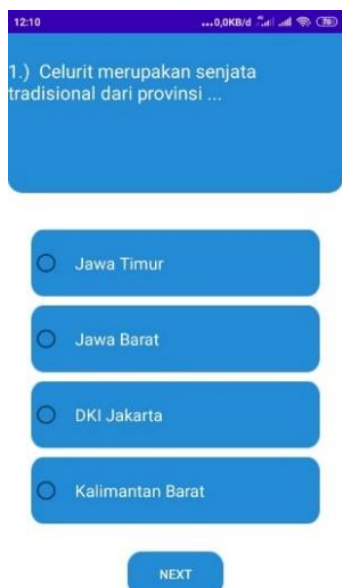

Gambar 11. Tampilan Menu Latihan Soal

Pada tampilan Menu Latihan Soal terdapat 10 buah pertanyaan yang dapat dijawab

\section{SIMPULAN}

Berdasarkan hasil implementasi aplikasi Pengenalan Seni Budaya Indonesia berbasis Android dapat disimpulkan bahwa aplikasi tersebut memberikan kemudahan untuk memperkenalkan kebudayaan Indonesia yang dapat diakses melalui perangkat smartphone berbasis Android (Wati, 2016). Aplikasi ini dapat digunakan dimanapun dan kapanpun melalui Smartphone berbasis Android. Karena Smartphone merupakan suatu media, baik itu pembelajaran, informasi, komunikasi, dan lainnya. Oleh karena itu, aplikasi ini memiliki kelemahan, yaitu hanya dapat dijalankan melalui Smartphone berbasis Android.

\section{DAFTAR PUSTAKA}

Ayu, I. G., \& Budiasih, N. (2013). Metode Grounded Theory Dalam Riset Kualitatif. Jurnal Ilmiah Akuntansi Dan Bisnis, 9(1), 19-27.

FURIYANTI, F. (2018). Oleh : Fatin Furiyanti Fakultas Teknik Program Studi Skripsi S1.

Gunawan, H., Septiana, Y., \& Gunadhi, E. (2020). Rancang Bangun Media Pembelajaran Pengenalan Ragam Budaya Indonesia Berbasis Android. In Jurnal Algoritma (Vol. 17, Issue 1). https://doi.org/10.33364/algoritma/v.17-1.82

Kusniyati, H., \& Pangondian Sitanggang, N. S. (2016). Aplikasi Edukasi Budaya Toba Samosir Berbasis Android. Jurnal Teknik Informatika, 9(1), 9-18. https://doi.org/10.15408/jti.v9i1.5573

Marzali, A. (2014). Memajukan Kebudayaan Nasional Indonesia. 26(3).

Maulana, A., Fauzi, A., Radiyah, U., \& Reynaldi, F. O. (2020). Perancangan Aplikasi Pengenalan Budaya Betawi Berbasis Android. Jurnal Infortech, 1(2), 68-72. https://doi.org/10.31294/infortech.v1i2.7098

Rahmat, F., \& Legiman, S. (2019). Perancangan Aplikasi Mobile Learning Berbasis Android Di SMK Negeri 6 Padang Rahmat Fadillah 1), Legiman Slamet 2) 1. Jurnal Vokasional Teknik Elektronika Dan Informatika, 7(2), 2.

Romzi, M. (2012). Logika dan Algoritma (Issue tahun 1736).

Saputra, A. W., Susano, A., \& Astuti, P. (2018). Rancang Bangun Aplikasi Edukasi Hardware Komputer Berbasis Teknologi Augmented Reality dengan Menggunakan Android. Faktor Exacta, 11(4), 310. https://doi.org/10.30998/faktorexacta.v11i4.3100

Wati, S. L. (2016). Implementasi Aplikasi Pengenalan Budaya Indonesia berbasis Android. Teknologi Informasi, 2(3), 137-141.

Yulisman, Y., \& Serdiansah, S. (2019). Aplikasi Pengenalan Kebudayaan Provinsi Riau Berbasis Android. Jurnal Teknologi Sistem Informasi Dan Aplikasi, 2(3), 79. https://doi.org/10.32493/jtsi.v2i3.3294. 